\title{
Novel composite sorbent AAm/MA hydrogels containing starch and kaolin for water sorption and dye uptake
}

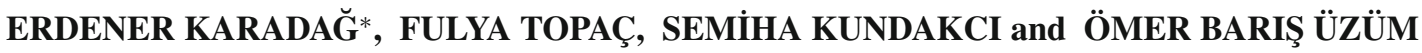 \\ Fen-Edebiyat Faculty, Chemistry Department, Adnan Menderes University, 09010 Aydın, Turkey
}

MS received 16 August 2013; revised 10 February 2014

\begin{abstract}
A novel polymer/clay composite sorbent based on acrylamide/maleic acid, starch and clay such as kaolin was synthesized with free radical solution polymerization by using ammonium persulfate/ $N, N, N^{\prime}, N^{\prime}-$ tetramethylethylenediamine as redox initiating pair in the presence of poly(ethylene glycol)diacrylate as a crosslinker. Surface morphology was characterized by the scanning electron microscopy technique. FT-IR analysis was used to identify the presence of different repeating units in the semi-interpenetrating polymer networks (semi-IPNs). Some swelling and diffusion characteristics were calculated for different semi-IPNs and hydrogels prepared under various formulations. The hydrogels were used in experiments on sorption of water-soluble cationic dye such as toluidine blue. Sorption of toluidine blue into the polymeric systems was studied by the batch sorption technique at $25{ }^{\circ} \mathrm{C}$. Water uptake and dye sorption properties of the crosslinked polymeric systems were investigated as a function of chemical composition of the hydrogels.
\end{abstract}

Keywords. Acrylamide/maleic acid; composite hydrogel; swelling; dye adsorption; starch; kaolin.

\section{Introduction}

A lot of synthetic and naturally derived materials have been studied to form well-characterized hydrogels. Natural polymers such as polysaccharides have been studied by many workers (Lanthong et al 2006; Patrickios 2010; Hu et al 2012; Jing et al 2013; Mahdavinia and Asgari 2013). Because of their specific properties, they have been used in many fields of biomedical and biotechnological applications. Starch (St) is a raw material of scientific and industrial process areas. St is a natural, renewable, and biodegradable polymer produced by plants as a source of stored energy. It can be found in many plants. There are two kinds of St: native and modified. The modified St has been used in many industrial and scientific applications. Grafting of acrylamide, acrylonitrile, methacrylonitrile, alkyl methacrylates, vinyl ketones and acrylic acid onto St has been investigated (Lanthong et al 2006; Murthy et al 2006; Güçlü et al 2010; Le Corre et al 2010; Patrickios 2010). St grafted copolymers have been used as hydrogels, flocculants, and ion exchangers (Lanthong et al 2006; Murthy et al 2006; Güçlü et al 2010; Le Corre et al 2010; Patrickios 2010).

The polymer/clay hydrogel composite has received great attention because of its relatively low production cost and high adsorption capacity for some dyes and metal ions ( $\mathrm{Li}$ and Wang 2005; Ekici et al 2006; Kaşgöz et al 2008; Kundakc1 et al 2008, 2009; Gu and Ye 2009; Güçlü et al 2010; Mahdavinia and Asgari 2013). To reduce costs and

\footnotetext{
*Author for correspondence (ekaradag@adu.edu.tr)
}

improve the comprehensive water-absorbing properties of superabsorbent materials based on acrylic monomers, grafting acrylic monomers onto clay and fabricating a composite consisting of a polymer and clay is a priority ( $\mathrm{Li}$ and Wang 2005; Ekici et al 2006; Kaşgöz et al 2008; Kundakc1 et al 2008, 2009; Gu and Ye 2009; Güçlü et al 2010; Mahdavinia and Asgari 2013). On the other hand, the development and characterization of nanostructured polymer/clay composites have received special attention because of the advantages in comparison to the traditional polymer composites. Minimal additions of nanoclay enhance mechanical, thermal, dimensional and barrier performance properties significantly because of the large contact area between polymer and clay on a nanoscale ( $\mathrm{Li}$ and Wang 2005; Ekici et al 2006; Kaşgöz et al 2008; Kundakc1 et al 2008, 2009; Gu and Ye 2009; Güçlü et al 2010; Mahdavinia and Asgari 2013). In many previous studies, several kinds of superabsorbent composites based on attapulgite, sepiolite, montmorillonite, kaolin (K) and bentonite were prepared and these superabsorbent composites showed high water absorbency and water retention, good salt resistance, and low production costs in comparison with pure organic superabsorbent polymers under the same preparation condition (Li and Wang 2005; Ekici et al 2006; Kaşgöz et al 2008; Kundakc1 et al 2008, 2009; Gu and Ye 2009; Güçlü et al 2010; Mahdavinia and Asgari 2013).

Water uptake property of hydrogels or 'hungry networks' account for a great number of biomedical and technological applications. Highly swollen polymeric gel with the ability to absorb water in high amounts is again under investigation, because of its potential applications in bioengineering, 
biomedicine, and other related areas (Barakat and Sahiner 2008; Yu and Xiao 2008; Moraes et al 2009; Ozay et al 2009; Kumari et al 2010; Li 2010; Kabiri et al 2011; Karada $\breve{g}$ and Üzüm 2012). Studies have been reported on the use of hydrogels or hydrophilic characteristic crosslinked polymers or copolymers as adsorbents for the removal of heavy metals, for the recovery of dyes, for removal of toxic or radioactive elements from various effluents and for metal pre-concentration for environmental sample analysis from aqueous solutions (Barakat and Sahiner 2008; Yu and Xiao 2008; Moraes et al 2009; Ozay et al 2009; Kumari et al 2010; Li 2010; Kabiri et al 2011; Karadağ and Üzüm 2012; Ortaboy et al 2013).

In this study, it was of interest to increase the water and dye sorption capacity of AAm hydrogels with highly hydrophilic functional groups containing chemical reagents such as maleic acid (MA) with St and K via the free radical solution polymerization method. Several MA-based studies by free radical polymerization were reported (Saraydın et al 1995; Bajpai 2001; Karadağ et al 2002; Murali et al 2006; Murthy et al 2006). Because of good compatibility, versatility, and non-toxicity, diprotic acids such as maleic acid have been studied by many workers in the preparation of acrylamide-based copolymeric hydrogels (Murthy et al 2006).

Here, in this work we have investigated the incorporation of St and K and MA into AAm hydrogel during free radical solution polymerization synthesis. AAm is a highly hydrophilic monomer, MA is an anionic monomer, $\mathrm{St}$ is a natural polymer and $\mathrm{K}$ is clay. On the other hand, some physical properties of hydrogels may be improved by preparing semi-interpenetrating polymer networks (semi-IPNs), when the hydrogel network is prepared in the presence of a previously made polymer such as poly(ethylene glycol), polyacrylamide, poly(N-isopropyl acrylamide), poly(vinyl pyrrolidone), poly(vinyl alcohol) or poly(acrylic acid) (Barakat and Sahiner 2008; Ozay et al 2009; Patrickios 2010; Karadağ and Üzüm 2012). Then, some swelling and some diffusional properties of AAm/MA, AAm/MA/St, AAm/MA/K and AAm/MA/St/K hydrogel systems were studied in water using dynamic swelling studies for swelling characterization. Water uptake and dye sorption properties of the hydrogel systems were investigated as a function of chemical composition of the hydrogels.

\section{Experimental}

Chemically crosslinked highly swollen acrylamide (AAm)/ maleic acid (MA) hydrogels were prepared by free radical crosslinking copolymerization of AAm (Merck, Schuchardt, Germany) monomer with addition of an anionic co-monomer such as MA (Merck, Schuchardt, Germany) and a multifunctional crosslinker such as poly(ethylene glycol)diacrylate (PEGDA, $M_{\mathrm{n}}=700$ ) as a crosslinker, which were supplied from Aldrich, Steinheim, Germany. Starch (St) was purchased from Carlo Erba, Rodana, Italy, and kaolin (K) was purchased from Fluka, Steinheim, Germany.
To prepare highly swollen AAm hydrogel systems, acrylamide weighing $1.0 \mathrm{~g} / 14.07 \mathrm{mmol}$ was dissolved in $1.0 \mathrm{~mL}$ water. Then, $20 \mathrm{mg} / 0 \cdot 1723 \mathrm{mmol}$ of MA were added to aqueous other AAm solution (for AAm/MA hydrogels containing $20 \mathrm{mg}$ MA). Then, $40 \mathrm{mg} / 0.3446 \mathrm{mmol}$, or $60 \mathrm{mg} /$ $0.5169 \mathrm{mmol}$, or $80 \mathrm{mg} / 0.6892 \mathrm{mmol}$ of MA were added to other aqueous AAm solutions, respectively for containing different amount of MA. After these additions, for the synthesis, $0.25 \mathrm{~mL} / 0.004 \mathrm{mmol}$ of $1 \%$ concentration of PEGDA, $0.2 \mathrm{~mL} / 0.044 \mathrm{mmol}$ aqueous solutions of ammonium persulfate (APS) $(5.0 \mathrm{~g}$ APS $/ 0.022$ $\mathrm{mmol} / 100 \mathrm{~mL}$ water) (Merck, Darmstadt, Germany) and $0.25 \mathrm{~mL} / 0.017 \mathrm{mmol} 1 \%$ concentration of $N, N, N^{\prime}, N^{\prime}-$ tetramethylethylenediamine (TEMED) (Merck, Schuchardt, Germany) were added to these aqueous solutions. The solutions were placed in poly(vinyl chloride) (PVC) straws of $3 \mathrm{~mm}$ diameter and these mixture samples were kept in a hot air oven at $70{ }^{\circ} \mathrm{C}$ for $30 \mathrm{~min}$. After gelation, fresh hydrogels obtained in long cylindrical shapes were cut into pieces of 3-4 mm in length. They were dried in air and vacuum.

AAm/MA/St composite semi-IPNs were prepared using the same preparation method. But, $1.0 \mathrm{~mL}$ of $1.0 \%$ aqueous St solution was used instead of distilled water in the related preparation method. To prepare highly swollen AAm/MA/St (containing different contents of St) semi-IPNs, same method was used as mentioned above with the addition of $1.0 \mathrm{~mL}$ of $0.5 \%$ aqueous St solution, $1.0 \mathrm{~mL}$ of $1.5 \%$ aqueous $\mathrm{St}$ solution, or $1.0 \mathrm{~mL}$ of $2.0 \%$ aqueous St solution containing $1.0 \mathrm{~g}$ AAm and $60 \mathrm{mg}$ MA.

For the preparation of AAm/MA/K and AAm/MA/St/K composite hydrogels, AAm/MA and AAm/MA/St hydrogels were placed in $1.0 \%$ kaolin $(\mathrm{K})$-water suspension systems, and they were mixed on the magnetic stirrer for 3 days.

For swelling studies, chemically crosslinked dried copolymeric hydrogels were accurately weighted and transferred into water. Water uptake with respect to time was obtained by periodically removing the samples from water; quickly blot drying, and reweighing. The measurements were taken at $25 \pm 0 \cdot 1{ }^{\circ} \mathrm{C}$ in a water bath.

Batch sorption studies were proceeding in all sorption experiments. Cationic dye, toluidine blue (TB) was used in sorption studies and some properties of TB are given in table 1 . Solutions of TB concentration ranging from $3.00 \times 10^{-5}$ to $6.00 \times 10^{-5} \mathrm{M}$ in distilled water were prepared. AAm/MA, AAm/MA/St, AAm/MA/K and AAm/MA/St/K hydrogel systems were used in a known volume of dye solution until equilibrium was reached. For MA, St and K effects on the dye sorption, aqueous solutions of concentration of $5.00 \times 10^{-5} \mathrm{M}$ of TB were used. After sorption, dye solution was separated by decantation from the hydrogels. Spectrophotometric method was applied to dye solutions. Spectrophotometric measurements were carried out using a SHIMADZU UV 1601 model UV-VIS spectrophotometer at an ambient temperature. The absorbances of these solutions were read at $626 \mathrm{~nm}$ for TB (Karadağ et al 2006, 2009). Distilled water was chosen as the reference. The equilibrium concentrations of the cationic dye solutions were determined by means of precalibrated scales. 
Table 1. Some properties of Toluidin Blue.

Toluidine Blue, Basic Blue $17(\mathrm{~TB})$

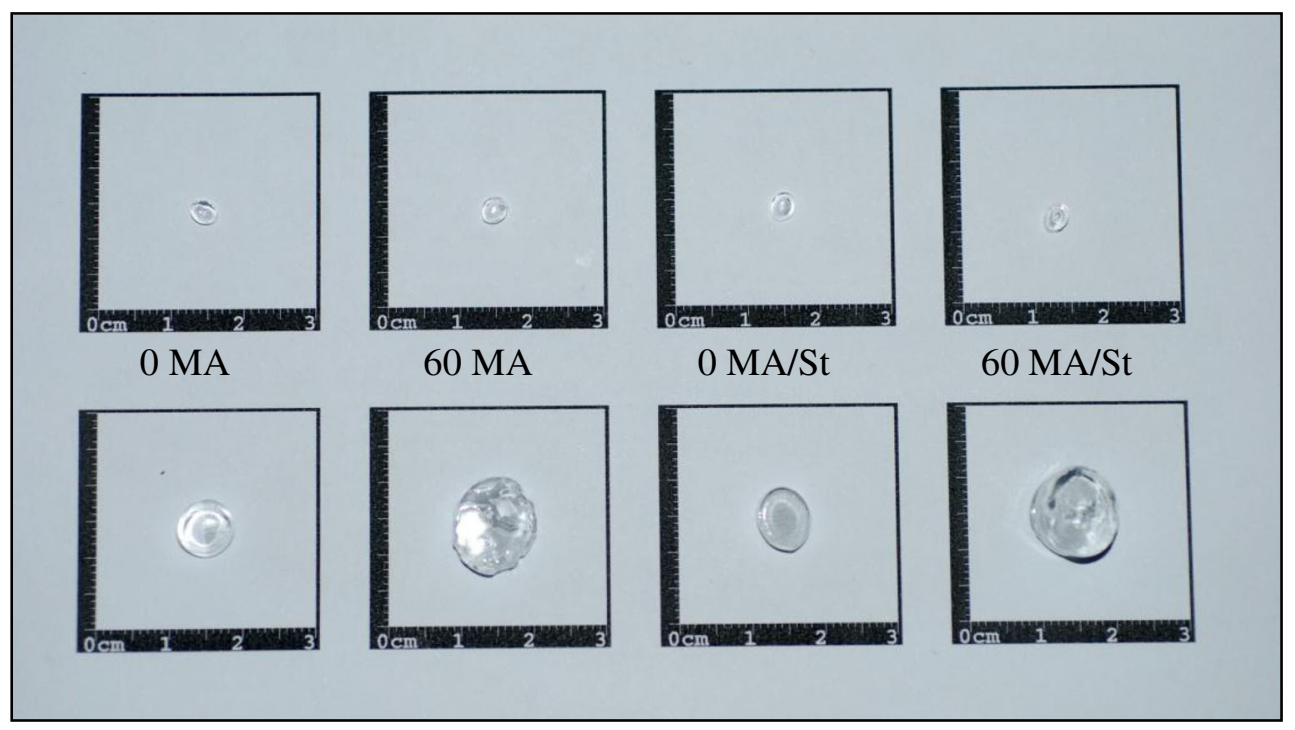

Figure 1. The photographs of AAm/MA and AAm/MA/St hydrogel systems (as dry state or swollen state).

For structural characterization, FT-IR analysis was made. Spectra were taken on $\mathrm{KBr}$ discs using VARIAN FTS 800 FT-IR spectrophotometer.

The surface morphology of AAm/MA, AAm/MA/St, AAm/MA/K and AAm/MA/St/K hydrogel systems was visualized by a scanning electronic microscope PHILLIPS XL30S FEG. For the characterization technique of the surface morphology of the samples, swollen samples were used.

\section{Results and discussion}

Highly swollen AAm/MA and AAm/MA/St hydrogel systems were prepared by free radical solution polymerization. The structure of copolymers is random. Then AAm/MA/K and $\mathrm{AAm} / \mathrm{MA} / \mathrm{St} / \mathrm{K}$ hydrogel systems were prepared by loading of K. Dried AAm/MA, AAm/MA/St, AAm/MA/K and $\mathrm{AAm} / \mathrm{MA} / \mathrm{St} / \mathrm{K}$ hydrogel systems are glassy and very hard, but swollen gels are soft. The photographs of the crosslinked polymeric systems are presented as dry state or swollen state in figure 1. Swelling of the hydrogels was strong enough to retain their shape.

\section{$3.1 \quad$ FT-IR analysis}

FT-IR spectra of the hydrogel systems were evaluated and are presented in figure 2. In figure 2, more wide peak at

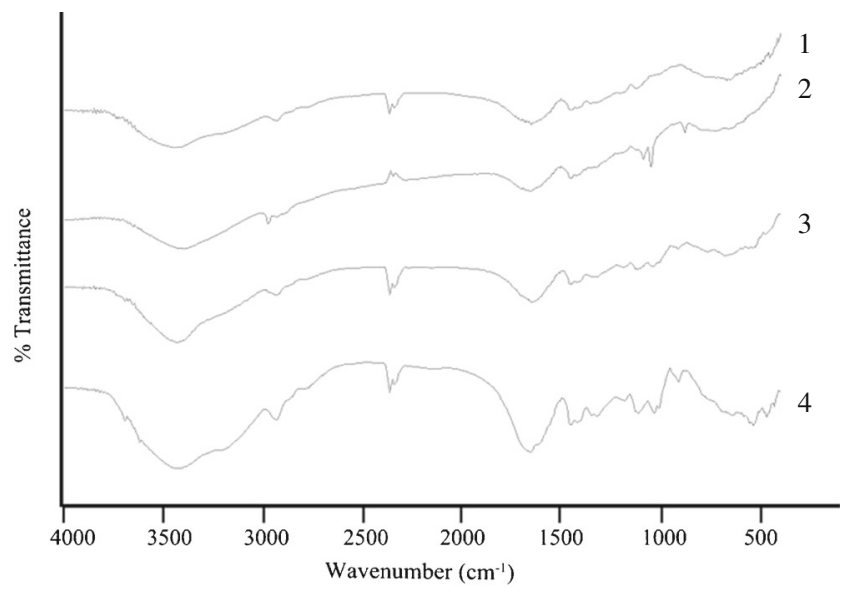

Figure 2. FT-IR spectra of the hydrogel systems containing of $60 \mathrm{mg}$ MA. (1) AAm/MA; (2) AAm/MA/St; (3) AAm/MA/K and (4) $\mathrm{AAm} / \mathrm{MA} / \mathrm{St} / \mathrm{K}$.

$3000-3500 \mathrm{~cm}^{-1}$ than spectra of AAm/MA is seen. The bands at $1600-1700 \mathrm{~cm}^{-1}$ could be attributed to a shift in stretching vibration associated with hydrogen that is bonded directly to an overtone of the strong carbonyl absorption. It is thought that the peaks at $3600-3700 \mathrm{~cm}^{-1}$ are $\mathrm{O}-\mathrm{H}$ bands and absorption peaks between 3400 and $3600 \mathrm{~cm}^{-1}$, which 
is due to stretching bands of the $\mathrm{OH}$ groups of MA and $\mathrm{K}$. Also, the peaks at $1110 \mathrm{~cm}^{-1}$ are $\mathrm{Si}-\mathrm{O}$ bands and the peaks at 900-980 $\mathrm{cm}^{-1}$ are Al-O-H bands for K. There may be some peaks at 1400 for the bands of $\mathrm{C}-\mathrm{N}$ for starch. The peaks observed between 1600 and $1700 \mathrm{~cm}^{-1}$ correspond to the $\mathrm{C}=\mathrm{O}$ of the acrylate unit of MA. The peaks observed in this region also correspond to the $\mathrm{C}=\mathrm{O}$ group of $\mathrm{AAm}$. On the other hand, it is thought that the peaks at $1250-1300 \mathrm{~cm}^{-1}$ are $\mathrm{C}-\mathrm{N}$ bands, and the peaks at $2800-2900 \mathrm{~cm}^{-1}$ and 1400 $\mathrm{cm}^{-1}$ show $-\mathrm{CH}_{2}-$ groups on the polymeric chain. Broad peaks between 3200 and 3600 and a sharp peak at approximately $1600-1700 \mathrm{~cm}^{-1}$ in the IR spectra of IPN hydrogel can indicate the presence of the AAm and MA units along with $\mathrm{S}$ and $\mathrm{K}$ repeating units in the polymeric hydrogels (Xu et al 2005; Lanthong et al 2006; Pourjavadi et al 2008; Patel et al 2011).

\subsection{Scanning electron microscopy (SEM) studies}

SEM is the most used technique to investigate the shape, size, morphology, crosslink and porosity of hydrogels or other related materials. Six SEM micrographs of the crosslinked copolymeric samples are presented in figure 3 as representative. The micro-structural differentiations can be followed from figure 3 . If figure 3 is examined, a lot number of porous and crosslinked structure can be seen.

\subsection{Equilibrium swelling studies}

The percentage swelling ( $S \%$ ) of the hydrogels in distilled water was calculated from the following relation:

$$
S \%=\frac{m_{\mathrm{t}}-m_{0}}{m_{0}} \times 100
$$

Here, $m_{\mathrm{t}}$ is the mass of the swollen gel at time $t$ and $m_{0}$ the mass of the dry gel at time 0 .

The water intake of initially dry hydrogels was followed for AAm/MA, AAm/MA/St, AAm/MA/K and AAm/MA/St/K hydrogel systems containing $60 \mathrm{mg} \mathrm{MA}$, and $1.0 \% \mathrm{~K}$ crosslinked by PEGDA in water, and swelling isotherms of AAm/MA/St hydrogels are shown in figure 4 as representative.

Figure 4 shows that swelling increases with time up to a certain level, then levels off. This value of swelling may be called as the equilibrium swelling percent $\left(S_{\text {eq }} \%\right)$. $S_{\text {eq }} \%$ values of AAm/MA, AAm/MA/St, AAm/MA/K and AAm/MA/St/K hydrogel systems containing $60 \mathrm{mg}$ MA, and $1.0 \% \mathrm{~K}$ are given in table 2 . Table 2 shows that $S_{\text {eq }} \%$ of AAm hydrogels is $1050 \%$, but $S_{\text {eq }} \%$ values of AAm/MA are $3200-5750 \%$ with the incorporation of MA groups into AAm hydrogels.

The values of $S_{\text {eq }} \%$ of AAm/MA/St semi-IPN hydrogels containing $1.0 \%$ St are 2815-5250\% with the incorporation of St into AAm/MA hydrogels, while $S_{\text {eq }} \%$ value of AAm/St hydrogels is $1055 \%$. On the other hand, $S_{\text {eq }} \%$ values of AAm/MA/K hydrogels containing $1.0 \%$ of $\mathrm{K}$ are 5770 10650 with the incorporation of $\mathrm{K}$ groups into AAm/MA hydrogels, while $S_{\mathrm{eq}} \%$ value of AAm/K hydrogels is 1175 . $S_{\text {eq }} \%$ values of AAm/MA/St/K semi-IPN hydrogels containing $1.0 \%$ St and $1.0 \% \mathrm{~K}$ are 3400-8135 with the incorporation of $\mathrm{St}$ and $\mathrm{K}$ into AAm/MA hydrogels, while $S_{\mathrm{eq}} \%$ value of $\mathrm{AAm} / \mathrm{St} / \mathrm{K}$ semi-IPN is 1170 (table 2). In table 2, $S_{\text {eq }} \%$ of the hydrogels increased with the MA content in the copolymers. $S_{\text {eq }} \%$ of AAm/MA, AAm/MA/St, AAm/MA/K and AAm/MA/St/K hydrogels is higher than $S_{\text {eq }} \%$ of AAm hydrogels.

MA contains a lot of ionizable/anionic groups $(-\mathrm{COOH})$. The increasing of the values of $S_{\mathrm{eq}} \%$ is due to an increase in the ionizable/anionic units. The hydrophilic group numbers of AAm/MA, AAm/MA/St, AAm/MA/K and $\mathrm{AAm} / \mathrm{MA} / \mathrm{St} / \mathrm{K}$ hydrogel systems are higher than those of AAm, and so the swelling values of AAm/MA, AAm/MA/St, $\mathrm{AAm} / \mathrm{MA} / \mathrm{K}$ and $\mathrm{AAm} / \mathrm{MA} / \mathrm{St} / \mathrm{K}$ hydrogel systems are greater than that of AAm swelling values.

It was shown that there was a decrease in the equilibrium swelling percent $\left(S_{\text {eq }} \%\right)$, of the semi-IPN systems when St was added to the hydrogel systems. Incorporation of St into the copolymer network leads to lower degrees of swelling. The reason of this is the polymeric structure of St. Here, it could be said that chains of St were placed in the crosslinked polymeric systems, instead of crosslinked AAm and MA groups. So, it was seen that there was a decrease in the value of the $S_{\mathrm{eq}} \%$, because of the decrease in hydrophilic character at crosslinked polymeric systems. But there was an increase in the $S_{\text {eq }} \%$ of the hydrogel systems when K was added to the hydrogel systems. It was seen that there was an increase in the value of the $S_{\text {eq }} \%$, because of an increase in the hydrophilic character at crosslinked polymeric systems.

The water absorbed by AAm/MA, AAm/MA/St, AAm/MA/K and AAm/MA/St/K hydrogel systems was quantitatively represented by equilibrium water content (EWC), and it can be calculated using the below equation (Saraydin et al 2004; Kundakc1 et al 2008, 2009; Karadağ and Üzüm 2012):

$$
\mathrm{EWC}=\frac{m_{\mathrm{eq}}-m_{0}}{m_{\mathrm{eq}}} .
$$

Here, $m_{\text {eq }}$ is the mass of the swollen gel at time $t$ (equilibrium), and $m_{0}$ the mass of the dry gel at time 0 .

The values of EWC of all AAm/MA, AAm/MA/St, AAm/MA/K and AAm/MA/St/K hydrogel systems were calculated. The values of EWC of the hydrogels are tabulated in table 2. They are changed between 0.9131 and 0.9908 . It is seen that there is an increase in the values of EWC, if MA has been added to the hydrogel systems. Here, the main effect is the hydrophilic character of MA groups.

\subsection{Diffusion}

The following equation is used to determine the nature of diffusion of water into hydrogels (Peppas and Franson 1983; 
Saraydın et al 2004; Kundakcı et al 2008, 2009; Karadağ and Üzüm 2012):

$$
F=\frac{M_{\mathrm{t}}}{M_{\mathrm{s}}}=k t^{n}
$$

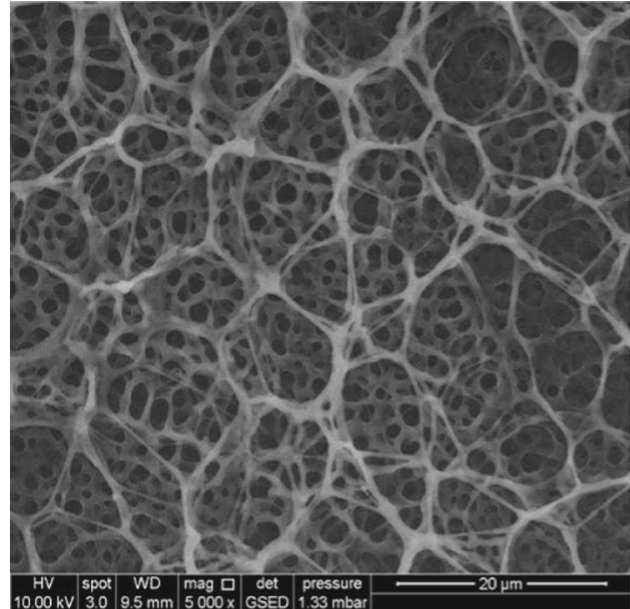

AAm

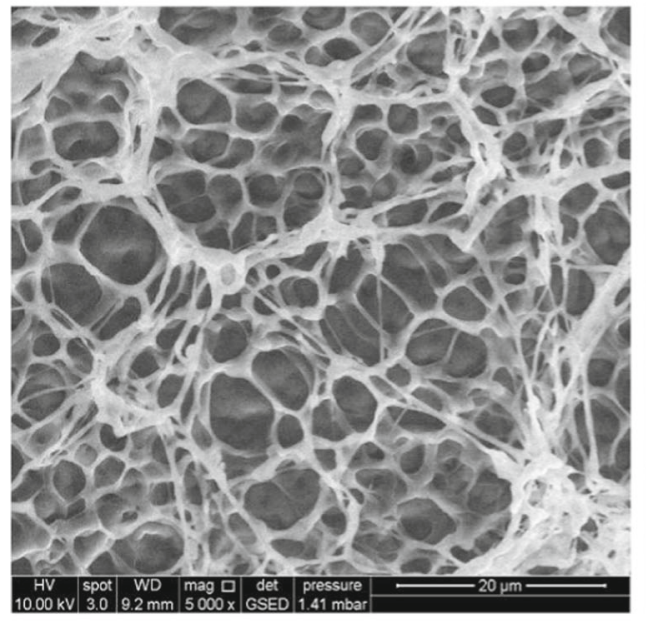

$\mathrm{AAm} / \mathrm{MA} / \mathrm{St}$

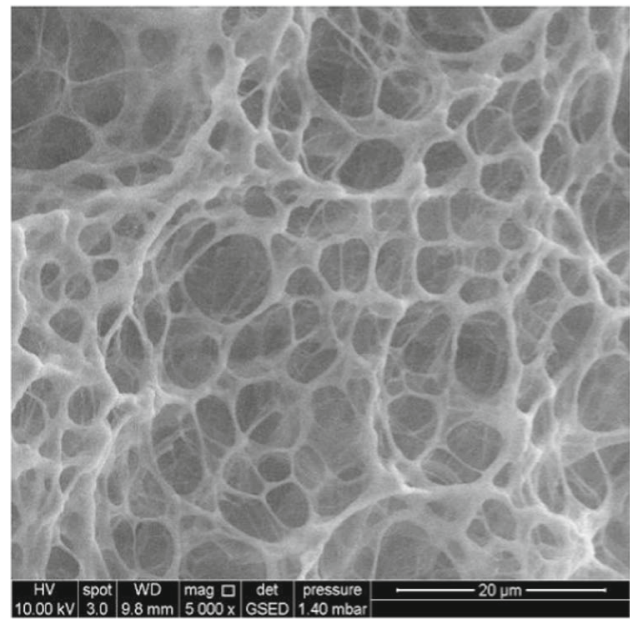

$\mathrm{AAm} / \mathrm{MA} / \mathrm{St} / \mathrm{K}$
Here, $F$ is the fractional uptake at time $t$ and, $M_{\mathrm{t}}$ and $M_{\mathrm{s}}$ the mass uptake of the solvent at time $t$ and the equilibrium, respectively. Equation (3) is valid for the first $60 \%$ of the fractional uptake. Fickian diffusion and Case II transport are defined by $n$ values of 0.5 and 1.0 , respectively. Anomalous

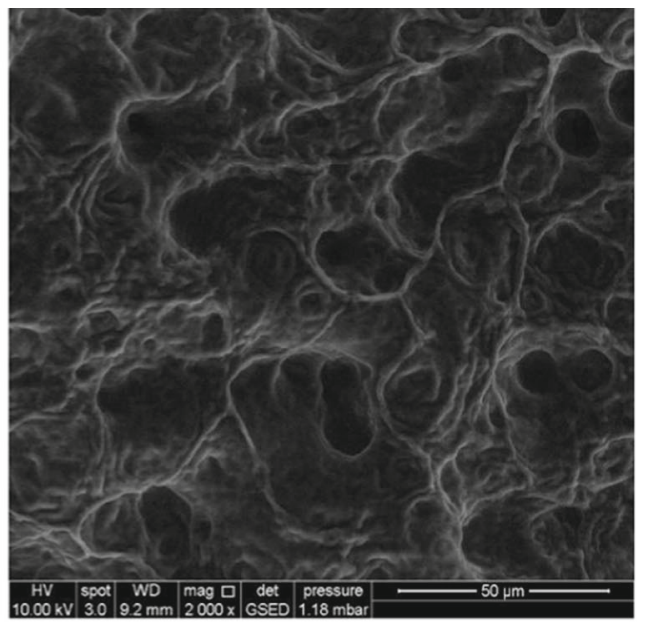

$\mathrm{AAm} / \mathrm{MA}$

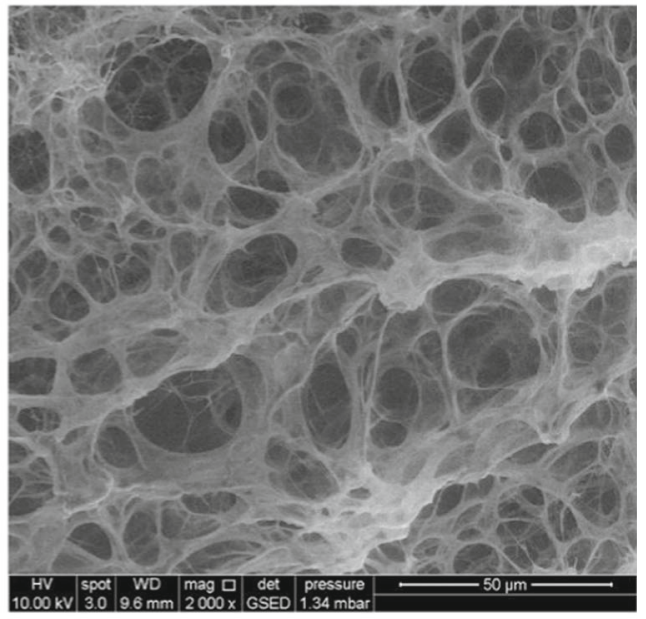

$\mathrm{AAm} / \mathrm{MA} / \mathrm{K}$

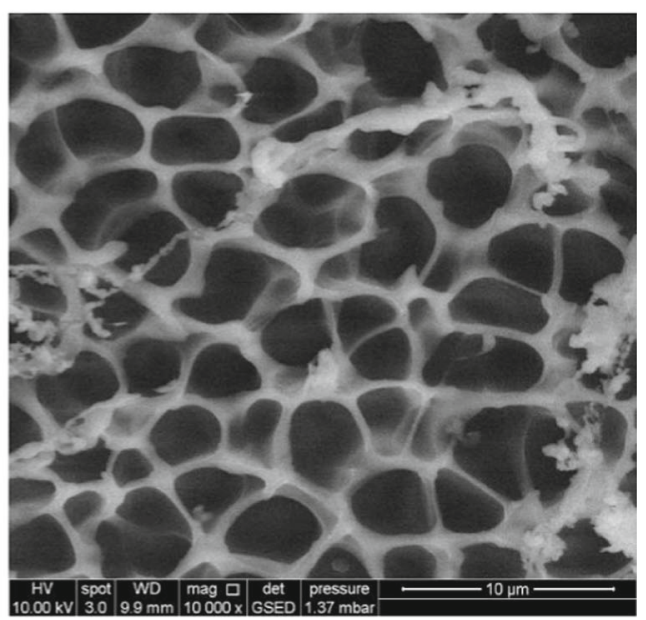

$\mathrm{AAm} / \mathrm{St} / \mathrm{K}$

Figure 3. SEM images of the hydrogel systems containing $60 \mathrm{mg}$ MA. 
transport behavior (non-Fickian diffusion) is intermediate between Fickian and Case II. This is reflected by $n$ between 0.5 and 1.0 (Peppas and Franson 1983; Saraydin et al 2004). The values of $n$ and $k$ were calculated from the slope and the intercept of the plot of $\ln F$ against $\ln t$, respectively.

For AAm/MA, AAm/MA/St, AAm/MA/K and AAm/ MA/St/K hydrogel systems, ln $F$ vs ln $t$ graphs are plotted and representative results are shown in figure 5. Diffusional exponents $(n)$ and diffusion constant $(k)$ are calculated and listed in table 3 .

Table 3 shows that the number determining the type of diffusion $(n)$ is over $0 \cdot 50$. Hence the diffusion of water into the hydrogel systems is generally found to have a non-Fickian character. When the diffusion type is anomalous behavior, the relaxation and diffusion time are of the same order of magnitude.

The study of diffusion phenomena of water in hydrogels is of value in that it clarifies polymer behavior. For hydrogel characterization, the diffusion coefficients can be calculated by various methods. The diffusion coefficient, $D$, of the water was calculated using the following equation

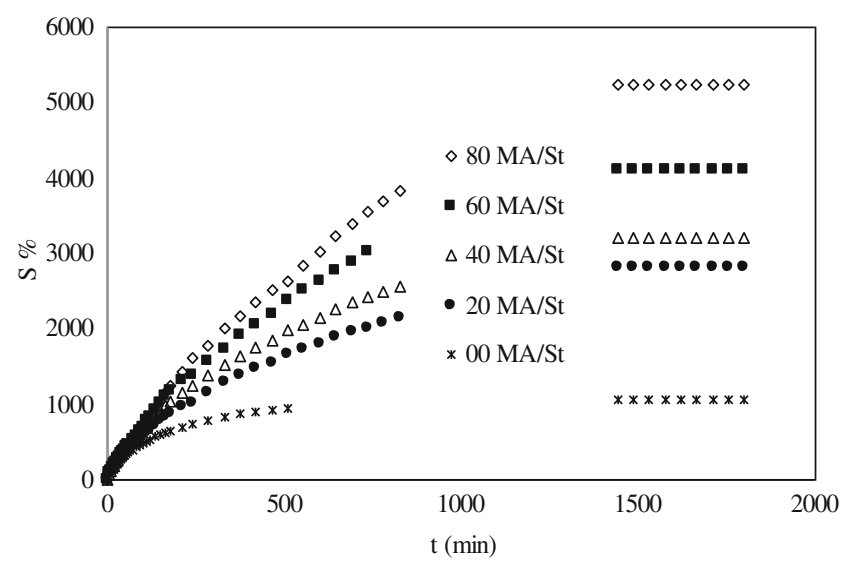

Figure 4. Swelling isotherms of AAm/MA/St semi IPN hydrogels.
(Dengre et al 2000; Çaykara et al 2006; Karadağ and Üzüm 2012):

$$
D=\pi r^{2}\left(\frac{k}{4}\right)^{1 / n} .
$$

Here, $D$ in $\mathrm{cm}^{2} \min ^{-1}, r$ the radius of a cylindrical polymer sample, $n$ the diffusional exponent and $k$ a constant incorporating characteristic of the macromolecular network system and the penetrant. The values of diffusion coefficient determined for AAm/MA, AAm/MA/St, AAm/MA/K and $\mathrm{AAm} / \mathrm{MA} / \mathrm{St} / \mathrm{K}$ hydrogel systems are listed in table 3 .

Table 3 shows that the values of the diffusion coefficient of the hydrogel systems vary from $0.45 \times 10^{-4}$ to $10.22 \times 10^{-4}$ $\mathrm{cm}^{2} \mathrm{~min}^{-1}$. It was seen that generally there was an increase in the values of the diffusion coefficient of the hydrogel systems by increasing of MA content. It can be said that there is no good relation between the values of the diffusion coefficient of the hydrogel systems.

\subsection{Starch and kaolin effect on the swelling and diffusion}

For investigation of the effect of mass/content of St and K on the swelling properties of AAm/MA/St and AAm/MA/St/K hydrogel systems containing $60 \mathrm{mg} \mathrm{MA}, 1.0 \% \mathrm{~K}$ and different contents of St such as $0.5 \%, 1.0 \%, 1.5 \%$ and $2.0 \%$, the related swelling isotherms and swelling kinetics curves of hydrogel systems were constructed and representative swelling isotherms are shown in figure 6. Effect of St and $\mathrm{K}$ on some swelling and diffusion parameters at AAm/MA/St and AAm/MA/St/K hydrogel systems containing $60 \mathrm{mg} \mathrm{MA}$, $1.0 \% \mathrm{~K}$ and different contents of St such as $0.5 \%, 1.0 \%$, $1.5 \%$ and $2.0 \%$ is tabulated in table 4 . For good characterization, changing of $S_{\text {eq }} \%$ values of the hydrogel systems by various contents of $\mathrm{St}$ is also shown in figure 6 .

It was shown that there was a decrease in the equilibrium swelling percent $\left(S_{\mathrm{eq}} \%\right)$ of the semi-IPN systems when $\mathrm{St}$ was added to the hydrogel systems. Incorporation of St into the copolymer network leads to lower degrees of swelling. The reason of this is the polymeric structure of

Table 2. Values of the equilibrium percentage swelling and equilibrium water contents of the hydrogels.

\begin{tabular}{lcccc}
\hline & AAm/MA & AAm/MA/St & AAm/MA/K & AAm/MA/St/K \\
\hline MA/mg & Equilibrium swelling percent $\left(S_{\mathrm{eq}} \%\right)$ & & \\
0 & 1050 & 1055 & 1175 & 1170 \\
20 & 3200 & 2815 & 5770 & 3400 \\
40 & 4345 & 3220 & 7495 & 4600 \\
60 & 5145 & 4095 & 10090 & 6040 \\
80 & 5750 & 5250 & 10650 & 8135 \\
& Equilibrium water contents (EWC) & & \\
0 & 0.9131 & 0.9135 & 0.9216 & 0.9212 \\
20 & 0.9697 & 0.9657 & 0.9830 & 0.9714 \\
40 & 0.9775 & 0.9699 & 0.9868 & 0.9787 \\
60 & 0.9809 & 0.9762 & 0.9902 & 0.9837 \\
80 & 0.9829 & 0.9813 & 0.9908 & 0.9879 \\
\hline
\end{tabular}


St. Here, it could be said that chains of St were placed in the crosslinked polymeric systems, instead of crosslinked AAm and MA molecules. So, it was seen that there was a decrease in the value of the $S_{\mathrm{eq}} \%$, because of the decrease in the hydrophilic character at crosslinked polymeric systems. But there was generally an increase in the $S_{\mathrm{eq}} \%$ of the hydrogel systems when $\mathrm{K}$ was added to the hydrogel systems. It was seen that there was an increase in the value of the $S_{\text {eq }} \%$, because the increase in the hydrophilic character at crosslinked polymeric systems.

\subsection{Equilibrium sorption studies}

To observe the sorption of toluidine blue (TB) onto AAm/MA, AAm/MA/St, AAm/MA/K and AAm/MA/St/K hydrogel systems containing $60 \mathrm{mg} \mathrm{MA}$, and $1.0 \% \mathrm{~K}$, the hydrogel systems were placed in aqueous solutions of TB and allowed to equilibrate for four days at $25^{\circ} \mathrm{C}$. At the

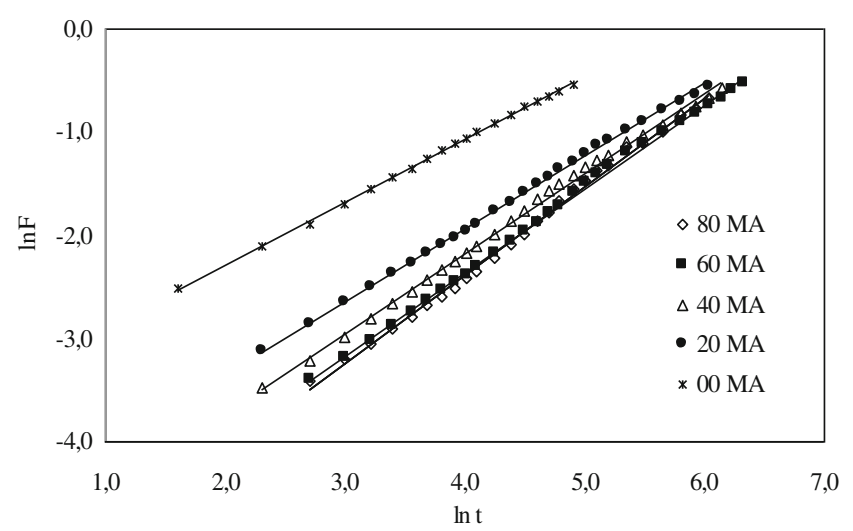

Figure 5. Swelling kinetic curves of AAm/MA hydrogels. end of this period, AAm/MA, AAm/MA/St, AAm/MA/K and AAm/MA/St/K hydrogel systems in the TB solutions showed the dark coloration. But AAm hydrogel did not sorb any dye from the solution.

In the sorption system at equilibrium, the total solute (dye) concentration, $C_{0}$, is calculated using the following equation (Molyneux 1984; Molyneux and Vekavakayanondha 1986):

$$
C_{0}=C_{\mathrm{b}}+C \text {. }
$$

Here, $C_{\mathrm{b}}$ is the equilibrium concentration of the solute (dye) on the sorbent per liter solution (bound solute concentration) and $C$ the equilibrium concentration of the solute in the solution (free solute concentration). The value of the bound concentration may be obtained using (5).

For equilibrium sorption studies, dye removal capacity $(q)$ (mass amount as 'mol' of sorption per unit mass (as gram)) of the adsorbent, adsorption percentage (Ads\%), and partition coefficient $\left(K_{\mathrm{d}}\right)$ can be investigated.

The dye removal capacity $(q)$ of AAm/MA, AAm/MA/St, AAm/MA/K and AAm/MA/St/K hydrogel systems containing $60 \mathrm{mg} \mathrm{MA}$, and $1.0 \% \mathrm{~K}$ was evaluated using the following equation:

$$
q=\frac{\left(C_{\mathrm{b}}\right) v}{m}
$$

where $q$ is the dye removal capacity of AAm/MA, AAm/ MA/St, AAm/MA/K and AAm/MA/St/K hydrogel systems $\left(\mathrm{mol} \mathrm{g}^{-1}\right), v$ the volume of the aqueous phase (L) and $m$ the mass of dry hydrogels. $C_{\mathrm{b}}$ has been defined earlier.

Adsorption percentage (Ads\%) of AAm/MA, AAm/ MA/St, AAm/MA/K and AAm/MA/St/K hydrogel systems was calculated using following equation:

$$
\text { Ads } \%=\frac{C_{0}-C}{C_{0}} \times 100 .
$$

\begin{tabular}{|c|c|c|c|c|}
\hline & $\mathrm{AAm} / \mathrm{MA}$ & $\mathrm{AAm} / \mathrm{MA} / \mathrm{St}$ & $\mathrm{AAm} / \mathrm{MA} / \mathrm{K}$ & $\mathrm{AAm} / \mathrm{MA} / \mathrm{St} / \mathrm{K}$ \\
\hline $\mathrm{MA} / \mathrm{mg}$ & \multicolumn{4}{|c|}{ Diffusion exponent $(n)$} \\
\hline 0 & $0 \cdot 61$ & 0.54 & $0 \cdot 67$ & 0.63 \\
\hline 20 & $0 \cdot 70$ & 0.70 & $0 \cdot 81$ & 0.71 \\
\hline 40 & $0 \cdot 77$ & 0.73 & $0 \cdot 91$ & $0 \cdot 78$ \\
\hline 60 & $0 \cdot 81$ & 0.76 & 0.92 & $0 \cdot 76$ \\
\hline \multirow[t]{2}{*}{80} & $0 \cdot 86$ & $0 \cdot 81$ & 0.99 & $0 \cdot 81$ \\
\hline & \multicolumn{4}{|c|}{ Diffusion constant $\left(k \times 10^{3}\right)$} \\
\hline 0 & $29 \cdot 85$ & $37 \cdot 61$ & $19 \cdot 37$ & $25 \cdot 59$ \\
\hline 20 & $8 \cdot 65$ & $7 \cdot 76$ & $4 \cdot 87$ & 8.68 \\
\hline 40 & $5 \cdot 16$ & $7 \cdot 08$ & $3 \cdot 21$ & $5 \cdot 33$ \\
\hline 60 & $3 \cdot 62$ & $5 \cdot 20$ & $3 \cdot 42$ & $5 \cdot 24$ \\
\hline \multirow[t]{2}{*}{80} & 2.98 & $3 \cdot 38$ & $2 \cdot 40$ & $3 \cdot 23$ \\
\hline & \multicolumn{4}{|c|}{ Diffusion coefficient $\left(D \times 10^{4}\right)\left(\mathrm{cm}^{2} \mathrm{~min}^{-1}\right)$} \\
\hline 0 & $1 \cdot 24$ & $0 \cdot 45$ & 1.63 & $1 \cdot 23$ \\
\hline 20 & 1.80 & $1 \cdot 25$ & $3 \cdot 23$ & $2 \cdot 19$ \\
\hline 40 & $2 \cdot 39$ & 1.64 & $5 \cdot 50$ & $2 \cdot 76$ \\
\hline 60 & $2 \cdot 73$ & $2 \cdot 16$ & $8 \cdot 18$ & $2 \cdot 61$ \\
\hline 80 & 3.94 & $2 \cdot 16$ & $10 \cdot 22$ & $2 \cdot 72$ \\
\hline
\end{tabular}

$C_{0}$ and $C$ have been defined earlier.

Table 3. Some diffusion parameters of hydrogel systems. 


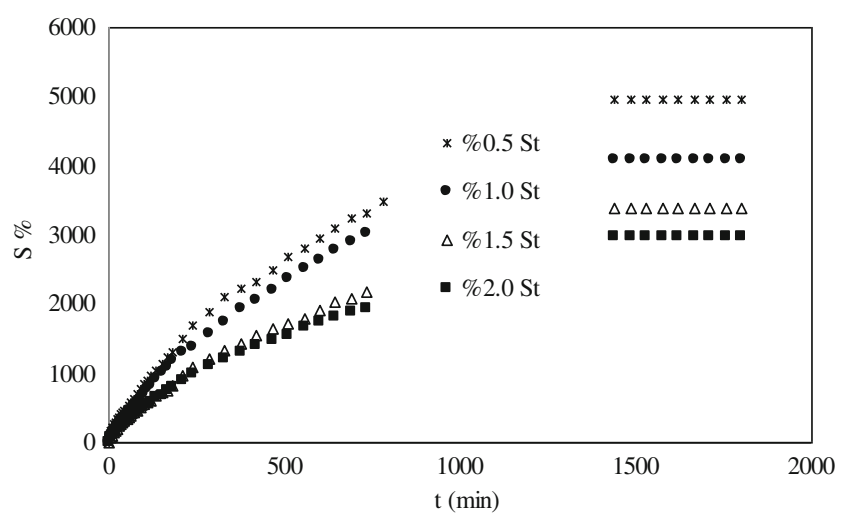

Figure 6. Swelling isotherms of AAm/MA/St hydrogels with various contents of St.
Firstly, uptake of dye measured effects of contents of MA. The dye removal capacity, that is, the amount of dyes sorbed onto unit dry mass of the gel was calculated for uptake of dye within the hydrogel in $5.00 \times 10^{-5} \mathrm{M}$ of TB in $\mathrm{L}$ of aqueous solutions and presented in table 5. Also, Ads\% of the hydrogel systems has been calculated and presented in table 5, too.

Table 5 presents the dye removal capacity of AAm/MA, AAm/MA/St, AAm/MA/K and AAm/MA/St/K hydrogel systems $\left(3.14 \times 10^{-6}-41.89 \times 10^{-6} \mathrm{~mol} \mathrm{~g}^{-1}\right)$ and their adsorption percentage $(24 \cdot 36-94.00 \%)$ is increased by increasing the content of MA. If the dye removal capacity and adsorption percentage of AAm/MA, AAm/MA/St, $\mathrm{AAm} / \mathrm{MA} / \mathrm{K}$ and $\mathrm{AAm} / \mathrm{MA} / \mathrm{St} / \mathrm{K}$ hydrogel systems are

Table 4. Some swelling and diffusion parameters of AAm/MA/St and AAm/MA/K hydrogels having of $60 \mathrm{mg}$ MA with different St and $1.0 \% \mathrm{~K}$ contents.

\begin{tabular}{|c|c|c|c|c|}
\hline Content of St & $0.5 \%$ & $1.0 \%$ & $1.5 \%$ & $2.0 \%$ \\
\hline \multicolumn{5}{|c|}{ Equilibrium swelling percent $\left(S_{\mathrm{eq}} \%\right)$} \\
\hline \multirow[t]{2}{*}{ Kaolin } & 4960 & 4095 & 3395 & 2965 \\
\hline & 7735 & 6040 & 4895 & 1715 \\
\hline \multicolumn{5}{|c|}{ Equilibrium water contents (EWC) } \\
\hline \multirow[t]{3}{*}{ Kaolin } & 0.9798 & 0.9762 & 0.9714 & 0.9674 \\
\hline & $0 \cdot 9872$ & 0.9837 & $0 \cdot 9800$ & $0 \cdot 9449$ \\
\hline & Diffusio & nent $(n)$ & & \\
\hline \multirow[t]{3}{*}{ Kaolin } & 0.79 & $0 \cdot 76$ & $0 \cdot 71$ & 0.71 \\
\hline & 0.78 & $0 \cdot 76$ & $0 \cdot 70$ & $0 \cdot 61$ \\
\hline & Diffusio & ant $(k \times$ & & \\
\hline \multirow[t]{3}{*}{ Kaolin } & 3.94 & $5 \cdot 20$ & $6 \cdot 29$ & $6 \cdot 65$ \\
\hline & $4 \cdot 30$ & $5 \cdot 24$ & $6 \cdot 64$ & $13 \cdot 13$ \\
\hline & Diffusio & cient $(D$ & $\left(\mathrm{cm}^{2} \mathrm{mi}\right.$ & \\
\hline \multirow[t]{2}{*}{ Kaolin } & $2 \cdot 83$ & $2 \cdot 16$ & $1 \cdot 35$ & 0.92 \\
\hline & $3 \cdot 53$ & $2 \cdot 61$ & 1.49 & 0.79 \\
\hline
\end{tabular}

Table 5. Some adsorption parameters of the hydrogel systems in aqueous solutions of TB.

\begin{tabular}{|c|c|c|c|c|}
\hline & $\mathrm{AAm} / \mathrm{MA}$ & $\mathrm{AAm} / \mathrm{MA} / \mathrm{St}$ & $\mathrm{AAm} / \mathrm{MA} / \mathrm{K}$ & $\mathrm{AAm} / \mathrm{MA} / \mathrm{St} / \mathrm{K}$ \\
\hline $\mathrm{MA} / \mathrm{mg}$ & \multicolumn{4}{|c|}{ Adsorption percentage (Ads\%) } \\
\hline 20 & $24 \cdot 36$ & 24.65 & $70 \cdot 90$ & $81 \cdot 51$ \\
\hline 40 & $30 \cdot 10$ & $31 \cdot 33$ & $78 \cdot 31$ & $85 \cdot 57$ \\
\hline 60 & $27 \cdot 27$ & $25 \cdot 16$ & $90 \cdot 80$ & $88 \cdot 84$ \\
\hline 80 & $34 \cdot 45$ & $42 \cdot 08$ & $89 \cdot 13$ & $94 \cdot 00$ \\
\hline \multicolumn{5}{|c|}{ Dye removal capacity $\left(q \times 10^{6}\right)\left(\mathrm{mol} \mathrm{g}^{-1}\right)$} \\
\hline 20 & $10 \cdot 20$ & $7 \cdot 03$ & $3 \cdot 14$ & $30 \cdot 97$ \\
\hline 40 & $9 \cdot 85$ & $8 \cdot 56$ & $4 \cdot 23$ & $29 \cdot 75$ \\
\hline 60 & $11 \cdot 65$ & $7 \cdot 93$ & $7 \cdot 80$ & $33 \cdot 15$ \\
\hline 80 & $13 \cdot 05$ & $12 \cdot 43$ & $7 \cdot 10$ & $41 \cdot 89$ \\
\hline \multicolumn{5}{|c|}{ Partition coefficient $\left(K_{\mathrm{d}}\right)$} \\
\hline 20 & $0 \cdot 32$ & $0 \cdot 33$ & $2 \cdot 44$ & 4.41 \\
\hline 40 & 0.43 & $0 \cdot 46$ & $3 \cdot 61$ & 5.93 \\
\hline 60 & $0 \cdot 37$ & $0 \cdot 34$ & $9 \cdot 87$ & $7 \cdot 96$ \\
\hline 80 & 0.53 & 0.73 & $8 \cdot 20$ & $15 \cdot 65$ \\
\hline
\end{tabular}




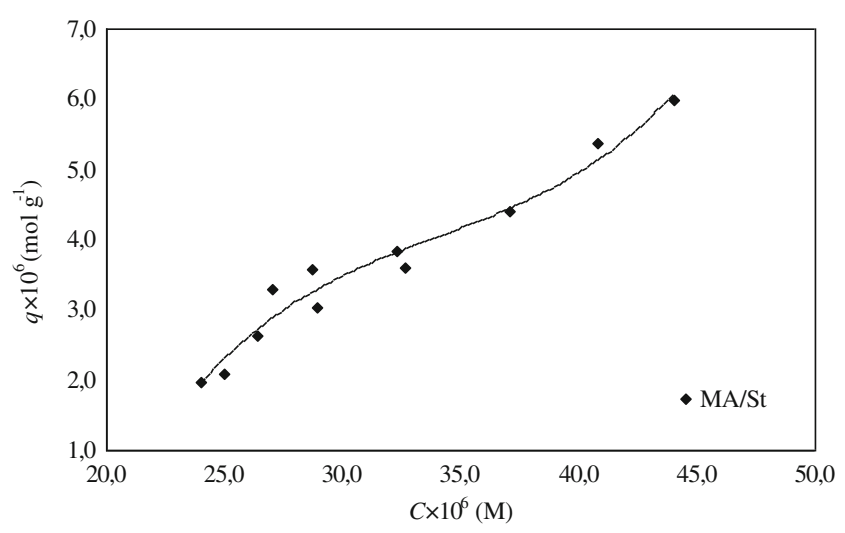

Figure 7. Equilibrium sorption isotherms of AAm/MA/St hydrogels in aqueous solutions of TB.

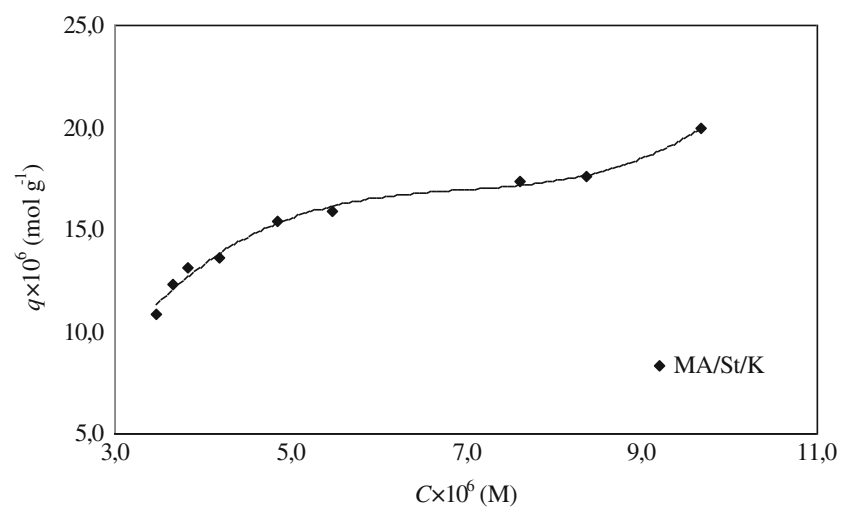

Figure 8. Equilibrium sorption isotherms of $\mathrm{AAm} / \mathrm{MA} / \mathrm{St} / \mathrm{K}$ hydrogels in aqueous solutions of TB.

Table 6. Some adsorption parameters of AAm/MA/St and AAm/MA/K hydrogels having of $60 \mathrm{mg}$ MA with different St and $1.0 \% \mathrm{~K}$ contents in aqueous solutions of TB.

\begin{tabular}{lcccc}
\hline Content of St & $0.5 \%$ & $1.0 \%$ & $1.5 \%$ & $2.0 \%$ \\
\hline \multirow{4}{*}{ Kaolin } & \multicolumn{1}{c}{ Adsorption } & percentage (Ads\%) & & \\
& 30.82 & 25.16 & 38.96 & 36.34 \\
& 86.08 & 88.84 & 84.19 & 81.65 \\
Kaolin & Dye removal capacity $\left(q \times 10^{6}\right)$ & $\left(\mathrm{mol} \mathrm{g}^{-1}\right)$ & \\
& 7.96 & 7.93 & 9.76 & 9.05 \\
\multirow{4}{*}{ Kaolin } & 24.40 & 33.15 & 25.21 & 22.51 \\
& Partition coefficient $\left(K_{\mathrm{d}}\right)$ & & \\
& 0.45 & 0.34 & 0.64 & 0.57 \\
& 6.18 & 7.96 & 5.33 & 4.45 \\
\hline
\end{tabular}

examined, it was seen that it was seen that there was not good relationship with the addition of St and K.

Partitioning of dissolved constituents between an aqueous phase and adsorbents in water and sediments has commonly been described by an empirical partition coefficient that simply relates the total concentration of a dissolved species to the total concentration of the adsorbed species (Şahiner et al 1998; Schwarte and Peppas 1998)

$$
K_{\mathrm{d}}=\frac{C_{\mathrm{b}}}{C}
$$

Here, $K_{\mathrm{d}}$ is the empirical partition coefficient at equilibrium. $C_{\mathrm{b}}$ and $C$ have been defined earlier. Partition coefficients of TB between dye solution and AAm/MA, AAm/MA/St, $\mathrm{AAm} / \mathrm{MA} / \mathrm{K}$ and AAm/MA/St/K hydrogel systems containing $60 \mathrm{mg} \mathrm{MA}$ and $1.0 \% \mathrm{~K}$ were calculated, and are shown in table $5 . K_{\mathrm{d}}$ values of the hydrogel systems range from 0.32 to 15.65 as shown in table 5 . Here, some of $K_{\mathrm{d}}$ values of the hydrogels are higher than 1.0. So, it can be said that synthesized AAm/MA, AAm/MA/St, AAm/MA/K and $\mathrm{AAm} / \mathrm{MA} / \mathrm{St} / \mathrm{K}$ hydrogel systems could be used as a potential water adsorbent (Şahiner et al 1998; Schwarte and Peppas 1998).
Equilibrium adsorption isotherms of AAm/MA, AAm/ $\mathrm{MA} / \mathrm{St}, \mathrm{AAm} / \mathrm{MA} / \mathrm{K}$ and AAm/MA/St/K hydrogel systems containing $60 \mathrm{mg} \mathrm{MA}$ and $1.0 \% \mathrm{~K}$ were plotted, and equilibrium adsorption isotherms of AAm/MA/St and AAm/MA/St/K hydrogels are presented in figures 7 and 8 .

In figures 7 and 8, the dye removal capacity (mol amount of sorption TB per unit mass) of the hydrogel systems is increased with the increasing concentration TB sorbed onto unit dry mass of the gel. The reason of this is the hydrophilic effect and dye sorption capability of co-monomer.

There can be many reasons for non-covalent interactions in the binding of TB by AAm/MA, AAm/MA/St, AAm/MA/K and AAm/MA/St/K hydrogel systems. The main interactions between the hydrogel and the monovalent cationic dye may be hydrophobic and hydrogen bonding. Specially, hydrogen bonding will be expected to occur between amine groups and nitrogen atoms on the dye molecules and the amine and carbonyl groups on the repeating units of crosslinked polymer. Hydrophobic effects are especially aqueous solutions interactions, which in the present case will involve those aromatic rings on the dye molecules and the methine and methyl groups on the gel. There can be some other interactions such as dipole-dipole and dipole-induced dipole interactions between the dye molecules and the hydrogel chains. 


\subsection{Starch and kaolin effects on the sorption of TB}

For investigation of starch (St) and kaolin (K) effects on dye sorption, some adsorption parameters such as dye removal capacity, adsorption percentage and partition coefficient of AAm/MA/St and AAm/MA/St/K hydrogel systems containing $60 \mathrm{mg} \mathrm{MA}, 1.0 \% \mathrm{~K}$ and different contents of $\mathrm{St}$ such as $0.5 \%, 1.0 \%, 1.5 \%$ and $2.0 \%$ contents in aqueous solutions of TB were calculated and are tabulated in table 6 .

It was shown that the values of the dye removal capacity of AAm/MA/St and AAm/MA/K hydrogels were between $7.93 \times 10^{-6}$ and $33 \cdot 15 \times 10^{-6} \mathrm{~mol} \mathrm{~g}^{-1}$. Also, incorporation of $\mathrm{St}$ and $\mathrm{K}$ into the copolymer network leads to different values of adsorption percentage (25.16-38.96\% for St addition and $81.65-88.84 \%$ for $\mathrm{K}$ addition) and partition coefficient (0.34-0.64 for St addition and 4.45-7.96 for $\mathrm{K}$ addition) of AAm/MA/S and AAm/MA/S/K hydrogel systems. But, it was said that if $\mathrm{K}$ chains were placed in the crosslinked polymeric systems, it was seen that it decreased the sorption parameters. Here, some of $K_{\mathrm{d}}$ values of the hydrogels are higher than 1.0. So, again, it can be said that synthesized AAm/MA/St/K hydrogel systems could be used as potential water adsorbent for removal of the dye molecules or other big molecular structures similar to dye molecules.

\section{Conclusions}

Incorporation of hydrophilic group containing chemicals such as maleic acid and the polymers such as starch and a clay such as kaolin in AAm hydrogels can be obtained successively by the free radical solution polymerization method. Multifunctional crosslinkers such as PEGDA were used in the polymerization process. AAm/MA, AAm/MA/St, $\mathrm{AAm} / \mathrm{MA} / \mathrm{K}$ and $\mathrm{AAm} / \mathrm{MA} / \mathrm{St} / \mathrm{K}$ hydrogel systems have showed high water absorbency. Some swelling and diffusion properties were discussed for different semi-IPNs and hydrogels prepared under various formulations. To determine the sorption characteristics of a cationic dye such as 'Toluidine blue' into the hydrogel systems, some sorption parameters have been calculated. For equilibrium sorption studies, dye removal capacity, adsorption percentage and partition coefficient of the hydrogel systems have been investigated. Consequently, AAm/MA, AAm/MA/St, AAm/MA/K and AAm/MA/St/K hydrogel systems developed in this study may serve as a potential device for water and dye sorbent. The use of these types of materials in agriculture, environment, separation and purification makes hydrogels more popular.

\section{References}

Bajpai S K 2001 J. Appl. Polym. Sci. 802782

Barakat M A and Sahiner N 2008 J. Environ. Manag. 88955

Çaykara T, Kiper S and Demirel G 2006 Eur. Polym. J. 42348

Dengre R, Bajpai M and Bajpai S K 2000 J. Appl. Polym. Sci. 761706

Ekici S, Işıkver Y and Saraydın D 2006 Polym. Bull. 57231
Gu Y and Ye L 2009 Polym. Plast. Technol. Eng. 48595

Güçlü G, Al E, Emik S, İyim T B, Özgümüş S and Özyürek M 2010 Polym. Bull. 65333

Hu Y, Yang T and Hu X 2012 Polym. Bull. 68309

Jing G, Wang L, Yu H, Amer W A and Zhang L 2013 Colloids Surf. A: Physicochem. Eng. Aspects 41686

Kabiri M, Emami S H, Rafinia M and Tahriri M 2011 Curr. Appl. Phys. 11457

Karadağ E, Kundakc1 S and Üzüm Ö B 2009 Polym. Plast. Technol. Eng. 481217

Karadağ E, Saraydın D and Işıkver Y Ç 2006 Polym. Plast. Technol. Eng. 45729

Karadağ E and Üzüm Ö B 2012 Polym. Bull. 681357

Karadağ E, Üzüm Ö B and Saraydın D 2002 Eur. Polym. J. 382133

Kaşgöz H, Durmuş A and Kaşgöz A 2008 Polym. Adv. Technol. 19213

Kumari A, Yadav S K and Yadav S C 2010 Colloids Surf. B: Biointerfaces 751

Kundakcı S, Üzüm Ö B and Karadağ E 2008 React. Funct. Polym. 68458

Kundakcı S, Üzüm Ö B and Karadağ E 2009 Polym. Compos. 3029

Lanthong P, Nuisin R and Kiatkamjornwong S 2006 Carbohydr. Polym. 66229

Le Corre D, Bras J and Dufrense A 2010 Biomacromolecules 11 1139

Li S 2010 Bioresource Technol 1012197

Li A and Wang A 2005 Eur. Polym. J. 411630

Mahdavinia G R and Asgari A 2013 Polym. Bull. 702451

Molyneux P 1984 Water-soluble synthetic polymers, properties and behavior (Boca Raton, FL: CRC Press) vol 2, p 118

Molyneux P and Vekavakayanondha S 1986 J. Chem. Soc. Faraday Trans. L 82291

Moraes I C F, Carvalho R A, Bittante A M Q B, Solorza-Feria J and Sobral P J A 2009 J. Food Eng. 95588

Murali M Y, Sudhakar K, Keshava M P S and Mohana R K 2006 Int. J. Polym. Mater. 55513

Murthy P S K, Murali M Y, Sreeramulu J and Mohana R K 2006 React. Funct. Polym. 661482

Ortaboy S, Acar E T, Atun G, Emik S, İyim B, Güçlü G and Özgümüş S 2013 Chem. Eng. Res. Des. 91670

Ozay O, Ekici S, Baran Y, Aktas N and Sahiner N 2009 Water Res. 434403

Patel A M, Patel R G and Patel M P 2011 J. Macromol. Sci. Part A 48339

Patrickios C S 2010 Macromol. Symp. 291-292 1

Peppas N A and Franson N M 1983 J. Polym. Sci. Polym. Phys. Ed. 21983

Pourjavadi A, Ayyari M and Amini-Fazl M S 2008 Eur. Polym. J. 441209

Şahiner N, Saraydın D, Karadağ E and Güven O 1998 Polym. Bull. 41371

Saraydın D, Karadă̆ E and Güven O 1995 Polym. Adv. Technol. 6719

Saraydın D, Karadağ E, Işıkver Y, Şahiner N and Güven O 2004 J. Macromol. Sci. A41 421

Schwarte L M and Peppas N A 1998 Polymer 396057

Xu Y X, Kim K M, Hanna M A and Nag D 2005 Ind. Crops Products 21185

Yu H and Xiao C 2008 Carbohydr. Polym. 72479 